\title{
DA GUERRA À PAZ: o nascimento de um ator social no contexto da "nova pobreza" urbana em Salvador da Bahia"
}

\author{
Maria Gabriela Hita* \\ Luciana Duccini ${ }^{* *}$
}

Este artigo apresenta uma análise sobre as relações entre pobreza e a formação de um bairro pobre de Salvador, ${ }^{2}$ tema relativo à ocupação do espaço urbano e à formação de novas identidades sociais num contexto de disputa por direitos de cidadania e de processos de redemocratização por que passou a sociedade brasileira desde a década de 80 , questionando certas teses amplamente difundidas que defendem que o avanço de ações e

\footnotetext{
* Professor-Doutor do Departamento de Sociologia da Universidade Federal da Bahia. Estrada de São Lázaro, 197. Cep: 40. 210-730 - Federação - Salvador-BA - Brasil.mghita@ufba.br

** Antropóloga, Doutora em Ciências Sociais pela Universidade Federal da Bahia, Bolsista Fapesb. luduccini@gmail.com

${ }^{1}$ Agradecemos o apoio financeiro da Fundação de Amparo à Pesquisa do Estado da Bahia- FAPESB (pelo fomento à pesquisa e concessão de bolsas), que possibilitou o desenvolvimento de dois projetos que integram esta pesquisa. Nossos agradecimentos especiais vão à valiosa colaboracão da socióloga Sheila Cavalcante (Bolsista AT2, pela FAPESB) na coleta e análise de dados, e a de Murilo Souza Arruda (Bolsista do PIBIC-UFBA), pela sistematização das informações dos bancos de dados hemerográficos deste artigo.

${ }^{2}$ Essa análise resulta de aspectos que foram objeto de pesquisa etnográfica realizada anteriormente e que integra um conjunto muito mais amplo de estudos sobre pobreza e metrópoles, a qual se encontra em plena fase de desenvolvimento.
}

políticas neoliberais, pela sua tendência à fragmentação, erradicaria qualquer possibilidade de construção de novos movimentos sociais ou identitários. $^{3}$

Para tanto, o artigo estrutura-se em quatro partes: a primeira contextualiza a emergência de uma "nova pobreza urbana" no momento atual, defendendo uma abordagem muticulturalista da análise, capaz de captar as interações sociais múltiplas e as identidades pessoais e coletivas, para além das situações de exclusão social, resultantes das condições econômicas. A segunda parte recupera as novas dimensões da ação coletiva e da participação cidadã, bem como a emergência de um ator social de pleno direito no espaço urbano, que se constitui durante sua luta por moradia e que diz respeito a processos materiais, mas também no âmbito cultural, na construção ativa de seu re-

${ }^{3}$ Gostaríamos ainda de manifestar nossos especiais agradecimentos ao Dr. Ronaldo Almeida pelo proveitoso processo de intercâmbio de relatórios de pesquisas entre equipes e a frutífera troca de idéias nesses três anos de pesquisa conjunta, que muito contribuíram na produção destes resultados. Ao Dr. John Gledhill, pelos seus valiosos comentários à primeira versão deste artigo, e à Profa Anete Ivo, pelas generosas sugestões de re-edição final. 
conhecimento e de sua identidade social. $\mathrm{O}$ artigo recompõe, na terceira parte, elementos empíricos da história de formação do Bairro da Paz até o presente, com base em dados no arquivo do CEAS e de depoimentos de alguns moradores, em especial de lideranças locais. Finalmente, a quarta e última parte sintetiza elementos da história do Bairro da Paz, no âmbito dos "novos movimentos sociais" que operam num sentido ativo da participação cidadã, mas também do reconhecimento social através de estratégias de auto-controle da imagem do bairro e de seus moradores, no espaço público da cidade.

\section{POBREZA, "NOVA POBREZA" E RECONHECl- MENTO}

Nas últimas décadas, alguns estudos têm apontado a formação de um novo tipo de "pobreza”, relacionada aos efeitos da reestruturação do mercado de trabalho e à retração da seguridade social, que jogam largos contingentes de trabalhadores em situação de maior fragilidade (Lavalle e Castello, 2004; Ivo, 2005; Labbé, 2006). Embora essa seja uma tendência mundial, os efeitos de tal reestruturação têm características particulares, a depender de processos históricos locais. Assim, no Brasil, onde nunca se alcançou uma situação de pleno emprego nem de ampla disseminação dos direitos sociais, como em países do velho mundo, às parcelas de trabalhadores - cuja situação se deteriorou face aos direitos sociais adquiridos entre 1930 e 1980 - somam-se aqueles que sempre se encontraram à margem dos processos produtivos formalizados, especialmente nos grandes centros urbanos (Schwartzman, 2004, p. 27-28, 31-33). No mesmo período, no entanto, verifica-se, contraditoriamente, uma ampliação dos serviços prestados pelo Estado à população, que aparecem nas estatísticas como melhorias nos índices de educação, saúde, moradia e infra-estrutura urbana. ${ }^{4}$ Esse in-

${ }^{4}$ No entanto, essas melhorias ocorreram a partir de uma base tão restrita, que não são capazes de acompanhar o próprio crescimento populacional urbano, argumentam alguns (Schwartzman, 2004; Lavinas, 2006), permitin- cremento, porém, não chega a reduzir os contingentes de pobres, as taxas de desemprego nem a violência urbana (Kowarick, 2002; Ferreira, 2000; Duhau, 2005). Tampouco as atuais políticas de combate à pobreza estariam, no entender de certos autores, enfrentando realmente o problema das relações estruturais que mantêm largas parcelas de população em condições de marginalidade frente a certos direitos sociais (Schwartzman, 2004; Ivo, 2005; Lavinas, 2006). ${ }^{5}$

A "nova pobreza" é descrita por alguns como um fenômeno urbano dos conjuntos habitacionais, pois o acesso à moradia (com serviços básicos e, muitas vezes, título de propriedade) foi solucionado apenas parcialmente, enquanto outros problemas se mantiveram ou se agudizaram. Essa situação acrescentaria uma dimensão de carências simbólicas às materiais, devido a suas próprias características, como a “... guetização, concentração geográfica e social da população pobre” (Labbé, 2006, p. 209). Já outra vertente de autores coloca a discussão em torno da "nova pobreza" nos termos de "direitos" e "cidadania”. Enquanto, para alguns, o cenário político e econômico atual trouxe uma retração de direitos alcançados em décadas anteriores - e uma conseqüente fragilização da capacidade de mobilização e ação dos setores mais pobres da sociedade -, para outros, essa perda de direitos não provocou necessariamente uma desmobilização das camadas populares, a exemplo do debate realizado no LARR Research Fórum intitulado From The Marginality Of The 1960s To The "New Poverty" Of Today. Autores como Jelin (2004), Roberts (2004) e Gledhill (2005) apontam para a imprevisibilidade das "reações" e apropriações locais, mesmo às políticas de alcance internacional.

do interpretações conflitantes acerca da efetividade ou não de ações estatais, a depender do recorte utilizado pelas pesquisas (se de teor micro ou macro sociológico). ${ }^{5}$ Ivo (2005) aponta uma tendência atual de se enfrentar os efeitos negativos da pobreza através de "técnicas de gerenciamento”, isto é, do desenvolvimento de programas de assistência a populações-alvo específicas. Tais programas, porém, não questionam as causas da pobreza, nem permitem a constituição de direitos sociais universais (Cf. Gohn, 2006). De um outro ponto de vista, é exatamente essa a "universalidade" dos direitos sociais e civis que vem sendo questionada atualmente pelos movimentos culturais e de minorias identitárias. 
É preciso ter em mente que não foi apenas "a pobreza" (com suas qualificações e carências) que mudou, mas todo o contexto urbano contemporâneo. ${ }^{6}$ As próprias cidades se transformaram e, com elas, suas formas de representação e os modos de articulação e luta em seu ambiente. Os atores sociais interagem nessa paisagem das cidades atuais de modos distintos. Assim, é possível pensar-se que as novas questões relativas à pobreza se fazem acompanhar também por novas formas de ação social. Partindo desse ponto de vista, é possível recolocar a questão da pobreza de maneira um pouco distinta. Assim, uma visão sobre a "nova pobreza" pode ser construída retomando algumas discussões centrais em autores que dialogam com teorias próximas ao multiculturalismo, à interculturalidade, à pluralidade dos modos de modernização etc.

Apesar das diversas polêmicas em torno desse termo, o "multiculturalismo" tem sido associado a um pluralismo cultural característico das sociedades de hoje, em especial nas grandes cidades. Face à heterogeneidade das identificações e experiências possíveis - de classe, raça, etnia, gênero, religião, estilos de vida, etc. - a interação social entre esses segmentos (em sua constante interseção) nos espaços públicos exige o reconhecimento da identidade do outro e, portanto, o reconhecimento de um novo tipo de direitos: os direitos culturais (Touraine, 2005). O caso analisado no presente artigo, de formação do Bairro da Paz, explicita como a questão do "reconhecimento do outro" pode vir associada a outras situações materiais, como precariedade de moradia e acesso ao mercado de trabalho. Mostra ainda como abordar a "nova pobreza”, de uma perspectiva marxiana e

${ }^{6}$ Para uma revisão de conceitos como o de pobreza, exclusão e inclusão social, desafiliação, entre outros, ver Hita e Duccini (2006).

${ }^{7}$ Bourdieu e Wacquant (2002), Touraine (2005), entre outros, chamam a atenção para a inconsistência da perspectiva multiculturalista, ora por seus usos pouco definidos, ora por pressupor uma fixidez das identidades nidos, ora por pressupor uma fixidez das identidades
nas sociedades plurais que não corresponde à sua dinâmica de interacão. Por isso, Touraine (2005) prefere fala de "interculturalidade" ou "pluralidade dos modos de modernização", mas está dialogando e tratando das mesmas questões que outros autores denominam de "multiculturalismo". também fenomenológica, o que nos permite pensar o fenômeno da pobreza e dos atores sociais tanto a partir das restrições estruturais a que estão submetidos, e das quais não podem escapar, como das suas renovada capacidade de atuar e intervir no curso de sua própria história, que é imprevisível.

Autores como Wievorka (apud Macagno, 2003) indagam sobre que significado o reconhecimento cultural pode ter para populações submetidas a forte exploração econômica ou relegadas a "bairros miseráveis e massivamente excluídos" do mercado de trabalho. Uma resposta possível a essa questão seria pensar que as políticas "do reconhecimento" são muito mais do que isso e possibilitam a conquista de benefícios sociais e econômicos. Em certa medida é o que se pode ver na história do Bairro da Paz, objeto deste estudo, uma vez que melhorias concretas têm sido alcançadas por sua população, embora ainda de modo insuficiente. Por exemplo, o bairro conta hoje com duas escolas municipais de ensino fundamental e uma estadual de ensino médio, além de um Centro de Saúde, os quais, no entanto, não conseguem suprir a demanda local de uma população de aproximadamente 60 mil habitantes, nem alcançam a qualidade necessária nos serviços que oferecem. Em um nível muito mais amplo, é também o que se pode observar em certas políticas públicas que vêm sendo implementadas (já desde o governo Fernando Henrique Cardoso e intensificadas com o programa Fome Zero, de Luís Inácio "Lula" da Silva), no sentido de levar benefícios materiais para populações deles excluídas, mesmo que através de ações focalizadas.

Ao tratarmos da formação do Bairro da Paz e de como essa história foi, de um lado, retratada pelos jornais impressos locais, e, de outro, como foi compreendida por vários atores que participaram dessa empreitada (como as associações de moradores, movimentos sociais que os apoiaram, setores da Igreja Católica e de partidos de esquerda), não se pretende destacar apenas as especificidades de um caso particular. Intenta-se ressaltar também o duplo movimento que ele revela, de apropriação de um espaço na cidade - por parte de populações 
denominadas de "sem teto" - e de construção de um reconhecimento atribuído por outros a essa localidade, em sua luta pelo direito de habitar. Assim, estudar problemas sobre a pobreza da cidade de Salvador através do exemplo do Bairro da Paz é uma forma privilegiada de compreender algumas facetas da própria dinâmica da cidade de Salvador. Esse caso ilumina problemáticas mais amplas e traz referências que vão além das fronteiras locais, permitindo lançar luz sobre articulações, usualmente não analisadas, entre atores diversos e com distintas posições de poder, revelando novas facetas da capacidade de sua ação social. Através da análise da luta dos moradores do Bairro da Paz pelo espaço e pelo reconhecimento, podemos perceber a diversidade de posições, interesses de agentes envolvidos, tais como os moradores do local, movimentos sociais, distintos setores da própria Igreja Católica, o poder público, o capital imobiliário, movimentos ecológicos, entre outros. Assim, uma perspectiva que releva a agência dos sujeitos investigados nos permite visualizar o "surgimento do Bairro da Paz" como ator social. Essa idéia contesta o pessimismo inerente a muitas análises sobre "nova pobreza", que focalizam somente a fragmentação social e a política provocada pelas forças e estruturas neoliberais. Claro que, ao se adotar essa visão, não se afirma que esses sujeitos estariam isentos da interferência dessas forças e influências e que a tendência à fragmentação não ocorra. Apenas significa reconhecer que essas forças não eliminam, em si mesmo, a capacidade de luta e de organização desses novos atores sociais.

Neste artigo, portanto, consideramos como "nova pobreza" situações resultantes de um processo de exclusão social que afeta, especialmente, a inserção no mercado de trabalho e a capacidade de geração de renda. Mas ela também abarca o âmbito das identidades pessoais e coletivas, em um contexto urbano de contato freqüente entre grupos muito distintos - em lugares como shoppings, praias, transportes coletivos e mesmo nas residências de camadas mais abastadas, onde alguns moradores de áreas pobres servem como empregados domésticos. Trata-se de um conjunto de relações sociais em contextos de globalização econômica, técnica e também cultural, numa época em que a questão urbana se redefine em outros termos, incluindo também o reconhecimento dos atores sociais situados em seu espaço. Em especial no lugar onde se encontra localizado o Bairro da Paz: o de um bairro muito pobre, cercado por terras altamente valorizadas, tanto imobiliária quanto ecologicamente. ${ }^{8}$

A "nova pobreza", desde a perspectiva que privilegia a agência, também estaria associada ao surgimento de novas formas de ação e de atores sociais caracterizados pela melhor inserção no âmbito cultural, pelo maior acesso a canais de comunicação, pela inserção em múltiplas redes de relação (que se comunicam entre si), por novas modalidades de relação com o Estado e pela vontade dos indivíduos de serem atores de sua própria existência, de construírem ativamente sua identidade, numa volta reflexiva para si, ouc como diz Touraine:

Essa consciência de nós mesmos só pode ser a consciência de nossa existência comum, de nossa interdependência e, portanto, da necessidade de reconhecer no outro não apenas aquele que está em relação com a mesma modernidade com que eu estou relacionado, mas aquele cuja história não está totalmente separada da minha história. (2005, p. 211)

No caso específico do Bairro da Paz, isso pode ser exemplificado pela ampla procura dos jovens pelo Telecentro de Inclusão Digital (programa do governo federal), da utilização da Internet e, sobretudo, pela formação de grupos "culturais" jovens, como os de dança e hip hop, o que permite a esses rapazes e moças uma circulação muito mais ampla por áreas centrais da cidade e até mes-

${ }^{8}$ Ver, por exemplo, os mapas comparativos dos bairros da cidade apresentados em Carvalho e Pereira (2006) ou os dados do IBGE, 2000, onde se observa que, enquanto as áreas vizinhas apresentam de 96,93 a $100 \%$ de residências abastecidas pela rede geral de água, no Bairro da Paz o índice cai para 46,63 a 90,12\% a depender da sub-área. Ademais o Bairro da Paz aparece, nesses dados, com os piores indicadores de pobreza da cidade de Salvador quando comparado ao de outros bairros pobres da cidade, com ocupações iniciadas nas décadas de 40 ou $60 \mathrm{~s}$. O Bairro da Paz é uma ocupação recente, datada da década de 80 . 
mo outros Estados e países em suas apresentações artísticas. Outro exemplo seria a existência de sete cooperativas de trabalho no local - de serviços de construção civil, moda, reciclagem, doces e salgados, artesanato em papel e trabalhos gráficos, produção de instrumentos musicais, detergentes e sapatos - as quais, com ou sem apoio financeiro do setor público ou privado, promovem oportunidades de obtenção de emprego e renda para os moradores do bairro. Enquanto se desenvolvia o presente estudo, estavam emergindo, na comunidade, duas novas cooperativas (para promoção de eventos e outra relacionada a temas ambientais), contando todas elas com o apoio técnico do SEBRAE e do Banco do Brasil, entre outras instituições estatais ou privadas presentes na proliferação de ações e de projetos desenvolvidos na e por atores da própria comunidade.

\section{NOVA POBREZA E NOVOS ATORES SOCIAIS, OU UM NOVO MODO DE FAZER POLÍTICA: a atuação cultural e simbólica}

Os clássicos movimentos sociais do século $\mathrm{XX}$ (como os sindicatos, movimentos pela terra, etc.), que concentravam suas reivindicações em torno da dimensão econômica, têm apresentado declínio nos graus de participação, enquanto emergem outras formas de associação que permaneceram ou tornaram-se mais vigorosas. Em contextos de pobreza urbana, as associações de cunho religioso ou "identitário", ${ }^{9}$ por exemplo, vêm apresentando, segundo alguns pesquisadores, maiores níveis de participação que os movimentos de teor político ou social de décadas anteriores (Castells, 2002; Lavalle; Castello, 2004, p. 79-80; Giddens, 2005; Touraine, 2005). Não se trata, apenas, de uma maior ou menor esfera abarcada pelas pautas de reivindicações, mas, sobretudo, de novas formas de atuação política, de modo que podemos

${ }^{9}$ Em especial, os movimentos feministas, as lutas por direitos sexuais - levantadas por homossexuais em geral - e os movimentos negros têm chamado atenção para questões identitárias e provocado transformaçôes na forma de pensar de sociedades inteiras. sugerir que a gestação de "novas" formas de pobreza corresponde a "novas" formas de participação social.

A reconstituição da história do Bairro da Paz mostra como o engajamento dos moradore ${ }^{10}-$ pela sua permanência no espaço, seguida da conquista de políticas públicas para o bairro e gestão da sua nova identidade - esteve inserido num grande movimento de lutas pelo direito à moradia, a partir do início da década de oitenta. Na cidade, esse movimento foi sustentado pelo Movimento em Defesa dos Favelados (MDF), que não é um movimento local isolado. Essas ações acompanharam uma tendência global identificada por Teixeira (2001), a do surgimento de novos atores políticos e sociais que lutam por seus direitos e conformam uma nova cultura política voltada para o respeito e a eqüidade, com vistas à consolidação e ao aperfeiçoamento da democracia, exercitando o que o autor chama de participação cidadã, ou como diria Jelin "o direito a ter direitos" (2004). A participação cidadã se dá através de ações coletivas implementadas pela sociedade civil e voltadas para a interação com o Estado, o mercado e a própria sociedade mais ampla. Apesar de ter um caráter essencialmente político, essas ações não são tentativas de substituição ou de tomada do papel do Estado. Muito menos estão reduzidas a mecanismos institucionais de intervenção, ou à mera prestação de serviços. ${ }^{11}$ Sua ênfase está “... no debate público das questões, proposição de alternativas, exigência de prestação de contas dos atos dos agentes públicos, e conseqüente responsabilização.” (Teixeira, 2001, p. 36)

Tais ações coletivas, indicadoras de uma

${ }^{10}$ Apesar da variedade de atores mencionados, que participaram na construção da história do Bairro da Paz, e da diversidade de interesses entre eles, consideramos, neste artigo, o próprio bairro como ator social em si mesmo, e privilegiamos, em particular, o Conselho de Moradores como uma vertente importante na construção dessa imagem do local. Apesar dos conflitos internos, percebe-se a existência de um desejo bastante compartilhado por todos os segmentos e lideranças sobre como desejam ser reconhecidos pelos outros.

${ }^{11}$ Teixeira distingue a participação cidadã da popular por sua posição frente ao Estado: a primeira assume uma postura mais propositiva, enquanto a segunda é geralmente caracterizada pelo seu maior enfrentamento do Estado (2001, p.32). 
cidadania ativa, que variam em graus de intensidade, formatos e objetivos perseguidos, surgem num contexto contemporâneo marcado por certa apatia civil e indiferença por qualquer ação de interesse coletivo. Segundo o autor, a participação cidadã é um movimento reativo ao contexto de globalização, à retomada do projeto político liberal, à crise do Estado de Bem-Estar nos países desenvolvidos e ao processo de redemocratização de países da América Latina. Esse ambiente marca o desgaste e a modificação de certo tipo de participação direta do "movimento popular" e deflagra a constituição de uma sociedade civil global, composta por uma heterogênea gama de organismos, articulados em redes sociais e eletrônicas, que atuam na criação de espaços públicos autônomos ou institucionais, que debatem e propõem alternativas para problemas sociais gerais. É nesse contexto que a participação nos âmbitos locais é aqui revista, pois levanta a questão da participação no poder local e suas relações com o contexto global.

No caso brasileiro, Teixeira identifica que as ações coletivas desenroladas no processo de redemocratização do país, em especial a partir dos anos setenta do século XX e sedimentadas na Constituição Brasileira de 1988, dinamizaram as ações em nível local, criando outros tipos de ações e organizações. Elas também são responsáveis pela constituição de uma sociedade civil que “... tematiza novas questões, cria novos espaços de participação, faz surgirnovas formas de organização e interlocução com os poderes públicos" (Teixeira, 2001, p.120; itálico nosso), e acaba por trazer, para a agenda nacional, a discussão e a busca de alternativas para uma série de questões sensíveis da sociedade, dentre as quais a luta pela moradia e a reforma urbana, com as quais a história de implantação do Bairro da Paz está em grande sintonia.

Por sua vez, Ivo (2005) aponta para a ambigüidade presente nas políticas públicas atuais de enfrentamento da pobreza, encontradas tanto nas agências multilateriais como em movimentos de caráter emancipatório, que podem acabar por reverter uma ação social reivindicativa e emancipatória no contrário do proposto, contribuindo para o re- forço de reformas das agendas de caráter liberal. De um lado, e desde a década de noventa, tem sido hegemônico - em muitas políticas públicas e setores da sociedade civil - o chamado discurso neoliberal, que retira do Estado o papel de mediador e regulador das relações de produção e distribuição econômica. Com isso, o poder público tem sido desresponsabilizado do enfrentamento à pobreza. De outro lado, porém, com o crescimento da visão dos "pobres como sujeitos ativos", várias formas descentralizadas e democráticas de geração e gestão de recursos têm tido espaço, ampliando a experiência de democratização iniciada em muitos países da América Latina a partir da década de oitenta do século XX e possibilitando a crítica a um modelo desigual de desenvolvimento (Ivo, 2005, p. 82-83). Dessa maneira, precisamos tanto compreender o escopo das organizações populares contemporâneas, quanto os limites de sua relação com o Estado e com organizações variadas, face às concepções diversas acerca da pobreza e das formas de combatê-la. Nas cidades brasileiras (e latino-americanas, de um modo geral), as reivindicações pelo direito à moradia têm, historicamente, ocupado um lugar de destaque nas organizações populares.

A participação cidadã envolve várias formas de atuação, institucionais ou não, incluindo uma dimensão expressivo-simbólica, na qual afloram elementos de identificação de uma comunidade, isto é, atuações que podem ter cunho lúdico ou educativo e que trabalham símbolos que passam a ser compartilhados como marcas de identidade. Essa forma de atuação refere-se a uma ampla gama de formas de participação que abarcam o envolvimento em associações e grupos comunitários, culturais, religiosos etc.

Assim, podemos perceber que a chamada participação cidadã coloca em foco a questão da articulação entre diversos atores e instituições, objeto que é especialmente destacado no relato da história do bairro. Um outro elemento que Teixeira (2001) também destaca na sua análise é que essa articulação não se dá numa relação vertical entre Estado e sociedade, mas numa multiplicação de 
relações entre participantes de estatutos diferentes, o que possibilita o êxito de uma mobilização social nesse contexto. Não se trata, portanto, somente da capacidade de pressionar o poder público, mas - também e principalmente - a dimensão da inter-relação entre agências, organismos e atores variados. Quanto maior for a capacidade de um grupo ou movimento para agregar inter-relações, maiores serão suas possibilidades de obter recursos (sejam eles materiais ou simbólicos) e lograr atingir seus objetivos.

A história da formação e consolidação do Bairro da Paz pode ser, pois, compreendida nos marcos da emergência tanto de novos problemas associados à pobreza urbana quanto de novas formas de associação e mobilização popular. A pobreza urbana contemporânea é resultado de processos múltiplos, que envolvem exclusão (ou a inclusão precária) no mercado de trabalho e na sociedade de consumo, o acesso restrito a serviços públicos e também a formação de novas identidades culturais (pessoais ou coletivas), sociais e políticas. Assim, a partir do estudo do bairro, podemos visualizar o surgimento de um ator social de pleno direito, que luta não somente por recursos materiais, mas também por uma melhor inserção cultural - acesso a informações, a canais atuais de transmissão e trocas de experiências - e, sobretudo, pela construção ativa de sua identidade como um lugar na cidade,,$^{12}$ ou o que Manuel Castells (2002) identifica como identidade de projeto.

A seguir, apresentamos o processo de mudança das formas interativas entre os atores do Bairro da Paz e o contexto mais abrangente, de forma a fazer emergir alguns elementos novos sobre esses movimentos de inclusão ou exclusão que acompanham a construção desses atores na sua reprodução, no contexto contemporâneo. Vale ressaltar que a formação desses atores é fundamentalmente marcada por dois contextos históricos distintos: o

${ }^{12}$ Um exemplo disso é o recém-fundado Fórum Permanente de Entidades Sociais do Bairro da Paz, que consiste numa "rede" de associações locais para proposição de melhorias, cobrança junto a órgãos públicos e desenvolvimento de ações conjuntas e do qual nossa equipe de pesquisa tem o prazer de ser parceira. primeiro, o dos movimentos de ocupação e resistência, e o segundo marcado pelas formas de reconhecimento legitimadas pela institucionalização do bairro. Esse reconhecimento não se dá apenas no plano material ou institucional, mas é também associado ao uso de recursos simbólicos, encaminhados como estratégia de reconhecimento dos próprios atores e, finalmente, reconhecidos pelas esferas públicas e pela mídia.

\section{ORGANIZANDO A INVASÃO PARA LUTARE CONSTRUIR A VIDA NA "PAZ"}

Nesta seção do artigo, procuramos relatar, com base em dados do CEAS, ${ }^{13}$ referentes ao Bairro da Paz, assim como informações coletadas em nossa pesquisa etnográfica, ${ }^{14}$ parte da história da formação do bairro e sua consolidação, até o presente. Sobretudo, buscaremos analisar a formação de um novo tipo de ator social, que bem exemplifica o que a literatura contemporânea tem destacado como "novos movimentos sociais", numa era de globalização, caracterizada pela importância e expansão do poder das redes de comunicação e informação sobre a vida das pessoas. Trata-se de uma era também marcada pela configuração de novas formas de precarização do trabalho e do cotidiano de largas parcelas da população nas grandes cidades. A análise do material ajuda a evidenciar e melhor fundamentar, empiricamente, a emergência desse novo tipo de atores e movimentos, definidos mais a partir de sua expressão cultural (identitária) e menos por processos ou dimensões sociais e políticas que os de décadas anteriores, dos quais se fala na Sociologia urbana contempo-

${ }^{13}$ O CEAS - Centro de Estudos e Ação Social - se autodefine como uma entidade jurídica sem fins lucrativos, integrada por jesuítas e profissionais leigos. Seu principal objetivo é desenvolver um trabalho políticoeducativo (de conscientização) com diversos setores populares, para favorecer e incentivar a tomada de iniciativas próprias e autônomas. $\mathrm{O}$ arquivo contém mais de vinte anos de notícias de jornais soteropolitanos e de relatórios internos do CEAS, relativos ao processo de sua assessoria na organização popular local. Nesse caso, destacam-se os relatórios do Pe. Confa, membro do CEAS, mas também pároco do bairro.

${ }^{14}$ Depoimentos de moradores que ali estão desde o início, em especial lideranças locais. 
rânea (Touraine, 2005; Castells, 2002; Giddens, 2005; Gohn, 2006; Teixeira, 2001).

O material utilizado para fundamentar a análise desta seção apoiou-se principalmente num banco de dados de jornais coletados pelo CEAS, nos principais periódicos locais (principalmente $A$ Tarde e Tribuna da Bahia), entre 1982 e 1997, e notícias do Diário Oficial dos últimos anos, desde 1997 (coletadas diretamente pela nossa equipe de pesquisa, devidoà interrupção da base de dados do CEAS), com mais de cem notícias revisadas no total. De maior importância foi a análise realizada a partir dos relatórios internos (preciosos diários de campo), gentilmente disponibilizados também pelo CEAS, escritos pelo primeiro pároco do local (Padre Confa), a respeito do desenvolvimento das primeiras ocupações no bairro, das mobilizações do Bairro da Paz junto a outras comunidade e do desenvolvimento de associações de moradores, até o nascimento do atual Conselho de Moradores do Bairro da Paz. Além disso, a pesquisa se apoiou, também, nas narrativas de lideranças locais, coletadas por nossa equipe em trabalho de campo, durante os dois primeiros anos de pesquisas no local, além de outra base complementar (menos densa) de dados hemerográficos disponibilizados pela AVSI - Associação de Voluntários Internacional. ${ }^{15}$

Ao analisar a formação de uma "identidade" do bairro para seus moradores e para a população em geral, é relevante confrontar as opiniões locais com as veiculadas na imprensa, uma vez que esta conforma a imagem que os “outros” têm sobre o morador do Bairro da Paz, constituindo a "mediação" simbólica entre o bairro e seu entorno, a cidade. O conjunto das matérias jornalísticas analisadas deixa perceber uma importante "virada" quanto à natureza do discurso sobre essa comunidade ao longo dos anos de sua formação e consolidação como bairro. Num primeiro momen-

${ }^{15}$ Esta instituição é atualmente responsável, junto à CONDER e à COELBA, pelo desenvolvimento de projetos de urbanização no subúrbio ferroviário (o famoso projeto "Ribeira Azul"), com financiamentos do Banco Mundial e do governo italiano. A AVSI, em parceria com CONDER, também elaborou um interessante projeto de urbanização e requalificação para o Bairro da Paz em 2000, o qual não foi implementado. to (até por volta de 1987), as matérias se referiam à área como a de uma “invasão”, e o destaque das notícias recaía sobre os altos índices de violência e o medo causado a moradores de áreas vizinhas. A mudança política do poder estadual, com a eleição de Waldir Pires, foi acompanhada por uma alteração significativa no enfoque dado ao bairro nos noticiários, cujo discurso passou a se concentrar sobre as "carências" sofridas e as péssimas condições de vida dos habitantes dessa área. A partir da renomeação do bairro, ${ }^{16}$ a ênfase e o tom das notícias mudaram novamente: agora o Bairro da Paz ingressa como ator num discurso de cidadania e luta por direitos (políticos, sociais e principalmente culturais), embora a imagem marcada pela violência não tenha sido de todo abandonada nem esquecida, e a toda hora seja recuperada pela mídia.

A primeira matéria conhecida sobre a "invasão" das Malvinas data de 09 de agosto de 1982, no jornal A Tarde, e relata que, alguns meses antes, já haviam se iniciado as ocupações nas terras da família Visco, localizadas na Avenida Paralela um dos principais vetores de crescimento imobiliário da cidade e que conecta o centro da cidade com o aeroporto internacional. A última matéria, publicada no jornal Tribuna da Bahia, data de 08 de junho de 2005, e noticia o crescimento de instituições no Bairro da Paz, destacando a participação da Santa Casa de Misericórdia nos seus principais investimentos. O que mais chama a atenção, na leitura de todo o material, é a forma pela qual o bairro é tratado pelo poder público, que mudou da estratégia da repressão pela força ao de fortes investimentos através de políticas públicas e financiamento de projetos, como se verá adiante. Percebe-se, assim, uma grande preocupação do poder público com aquela localidade, tanto no início das invasões quanto após 1987, quando come-

\footnotetext{
${ }^{16}$ A renomeação da ocupação desse bairro inverteu semanticamente o sentido estigmatizado da primeira nomeação do local: Malvinas (em referência à guerra) para a de Bairro da Paz, nomeação de logradouros como Rua da Resistência, do Sossego, da Paz Celestial, etc. Inversão semântica similar às do par "inferninho" e "alta vista (céu)", "mal" e "bem", intencionando promover melhoria de auto-estima em setores estigmatizados pela sociedade. Essa vem sendo uma clara e ideologizada estratégia adotada por setores progressistas da Igreja católica, em suas diversas ações sociais.
} 
ça a fase de consolidação do bairro. É a partir dessa época que os jornais mudam o teor das notícias e já veiculam em suas manchetes a renomeação do "Bairro da Paz", não mais denominado Malvinas. Os meios de comunicação vão abandonando as notícias sobre o bairro, conforme avança sua consolidação. Entre o início da década seguinte até o ano de 2005 , quase não se menciona mais o Bairro da Paz nos periódicos locais. As notícias migraram para o Diário Oficial do estado da Bahia, que passa a divulgar as ações de urbanização, infraestrutura e combate à pobreza no bairro. O governo, que antes reprimia a invasão, hoje anuncia seus feitos para melhorar as condições de vida dos residentes locais. ${ }^{17}$ Essa mudança pode ser interpretada como um novo status alcançado pelo bairro nesse processo: de notícia das páginas policiais passou a ser objeto do Diário Oficial.

É perceptível uma atenção especial com as Malvinas, embora não tenha sido esse um movimento isolado ou único na cidade de Salvador. Mas, sem sombra de dúvidas, constitui um dos mais conhecidos e emblemáticos, pela sua especificidade e combatividade, ${ }^{18}$ pois nenhuma outra ocupação de terras demandou uma intervenção de força tão sistemática como a aplicada contra as Malvinas. Essa ocupação se ergueu - e o nome apontava para isso - como um exemplar e surpreendente ato de resistência de um fraco agrupamento de favelados contra o de uma agressiva e imperialista "potência bélica": o Estado, no auge de sua força repressora. As lutas por moradia, na década de oitenta, podem ser consideradas como um marco nessa mudança de paradigma anunciada por

${ }^{17}$ A mudança da postura governamental para com o Bairro da Paz coincide com uma modificação das políticas públicas para ocupações precárias. Em geral, de uma vertente mais autoritária, que agia através do "desmonte" e remanejamento das "invasões", passa-se para uma outra de "requalificação dos bairros pobres" (com todas as críticas que essa postura possa ter), associada à participação civil (Gordilho, 2000; Teixeira, 2001).

${ }^{18}$ É importante notar que o MDF, ao qual a ocupação das Malvinas se associou, surgiu vinculado à Igreja Católica em São Paulo, na década de 70, lutando por melhorias nas condições de moradia em favelas, como iluminação e saneamento básico. Na época das Malvinas, a organização dos moradores locais integrou-se a esse movimento muito mais amplo e que abarcou lutas por moradias de várias outras localidades. As Malvinas era uma das mais combativas na época.
Touraine (2005), uma vez que colocam em pauta não somente a obtenção de recursos materiais, mas também o direito ao "reconhecimento" das comunidades como atores participativos na sociedade e o direito de receberem outro tipo de atenção por parte das políticas públicas no acesso a serviços (de moradia, educação, saúde) dos quais estiveram sempre excluídos, como veremos mais adiante, através das organizações de moradores do Bairro da Paz em busca não apenas de serviços e direitos, mas também da libertação de um estigma.

As primeiras notícias analisadas na base de dados consultada relatam um maior uso de força contra os invasores do terreno. Essas matérias começaram a aparecer no ano de 1982, mas os primeiros a se estabelecerem no bairro começaram a chegar por volta de 1980 e 1981, em pequenas levas. Em 1982, os fluxos migratórios para o terreno tiveram um acréscimo acentuado, o que despertou a atenção pública para aquele movimento. A referência à contínua chegada de pessoas ao longo dos anos é recorrente e motivo de crescente preocupação estatal e de outros interesses imobiliários pelo local.

A região invadida está localizada num vetor de crescimento nobre da cidade, situado na Avenida Paralela, que conecta o centro da cidade ao Aeroporto e à linha verde (expansão hoteleira e turística da cidade) no litoral Norte do estado. Situa-se nas proximidades do Centro Administrativo e de outros grandes investimentos que apareceram depois dessa comunidade, como o Alphaville, a Universidade FTC, e uma grande área de ocupação residencial de classe média, denominado Imbuí, todos na Avenida Paralela, não muito distante do tradicional e primeiro Shopping da cidade, o Iguatemi, e agora também do recém inaugurado e elitizado Shopping Salvador. ${ }^{19}$

O terreno ocupado pela invasão das Malvinas pertencia à família Visco, e corresponde a uma grande área em meio a uma zona de Mata

${ }^{19}$ Em Carvalho e Pereira (2006), aparecem excelentes mapas da cidade de Salvador, alguns que apontam os principais vetores de expansão da área, e outros, todos georeferenciados, com diversos indicadores sociais comparativos das distintas ARs de Salvador. A área referente ao Bairro da Paz aparece com os piores indicadores da cidade. 
Atlântica, onde surgiram, mais tarde, luxuosas residências em condomínios fechados. Nos relatos atuais dos moradores, sempre há referências a esses vizinhos ricos. Este "fantasma" do valor do terreno parece ter estado presente nas preocupações da comunidade há um bom tempo e ter sido um elemento que polarizou a presença de diversos atores da sociedade civil. Outro fator relevante, nesse campo de disputas, é a importância ecológica da região. Concentrando lagoas, rios e remanescentes de mata atlântica, a área, ainda hoje, é considerada uma reserva ambiental da cidade, sendo defendida por grupos ecológicos que lograram impedir a expansão imobiliária no local durante alguns anos. Sob esse ponto de vista, a permanência da invasão dessa comunidade terminou operando indiretamente em favor dos interesses imobiliários, apesar da continuidade dos protestos do setor ambientalista. ${ }^{20}$ Atualmente, encontra-se em curso também a instalação de um parque tecnológico, nas imediações dessa região.

Nos relatórios do CEAS do início da década, e em diversos trechos dos jornais, observa-se que, no contexto do uso da força contra a ocupação, a reação dos moradores foi a sua organização e mobilização de modo crescente, com o passar do tempo. Essa mobilização ${ }^{21}$ contou com o apoio de associações envolvidas com direitos civis, como o próprio MDF, políticos de esquerda e membros da Igreja Católica em duas formas de atuação um tanto distintas. ${ }^{22}$ Enquanto, nas notícias de jornais, a

${ }^{20}$ Uma das muitas especulações sobre a diversidade de grupos que pleiteavam a posse de terras na Paralela, naqueles tempos, insinuava que uma parte dessas terras foi invadida por pobres e a outra vendida por baixo valor ou loteada por grandes construtoras (uma delas a OAS cujos proprietários são familiares do falecido senador Antônio Carlos Magalhães), que teriam interesses em empreitadas grandiosas, como algumas das que surgiram depois dos anos 80.

${ }^{21} \mathrm{O}$ primeiro grupo comunitário, nascido da iniciativa dos moradores, de que se tem notícia foi a Associação Beneficente Unidos Venceremos. Essa associação foi fundada por um grupo de mulheres, e teve uma líder comunitária como figura proeminente. Como acabou por se tornar uma marca desse processo inicial de mobilização, que tinha como ponto focal garantir a continuidade no local, é lembrada com afeto por muitos dos moradores mais antigos. Atualmente, a instituição tem pouca expressividade no bairro.

${ }^{22}$ Uma delas é a representada pelo CEAS (ligado à Teologia da Libertação), com seu caráter de "formação de bases". A outra é representada por Ernestina, leiga italiana que organização e resistência dos moradores tinham pouco espaço, nos relatórios do CEAS há longas descrições desses movimentos. Ou seja, se a associação de moradores emergia como protagonista das disputas pelas terras para organizações de apoio ao movimento, os discursos dos jornais mantinham uma grande ambigüidade entre retratá-las como uma luta por direitos de habitação ou como uma "massa ameaçadora" aos interesses e à segurança das classes médias vizinhas.

Uma das primeiras matérias desse acervo do CEAS data de 1983. Nela consta informação sobre uma reunião com mais de mil moradores para debater a proposta da prefeitura de transferilos para outras localidades, no subúrbio da cidade. O local utilizado, à época das ocupações, para os debates e deliberações chama-se, hoje, Praça das Decisões. ${ }^{23}$

No dia 17 de março de 1983 (após uma grande ação do governo na derrubada de barracos, em 10 de agosto de 1982), os jornais apontam um movimento organizado dos moradores para resistir às investidas do poder público. Informam, também, as propostas da prefeitura no remanejo de duas mil famílias do local. As informações minuciosas dos registros do CEAS corroboram as veiculadas nos jornais da época. Esse cruzamento de informações, ao longo dos anos, dá uma dimensão da amplitude da organização e da resistência desses e de outros moradores da cidade em situações semelhantes às do Bairro da Paz. Essa mobilização foi uma das sementes que contribuiu para a efervescência associativa política e cultural do bairro hoje e revela, já desde aquela época, uma

contou com muitos recursos internacionais (oriundos da sua paróquia em Mantova, Itália) para o bairro e pela Fundação Dom Avelar, com apoio da Santa Casa de Misericórdia. Os modos de atuação de Ernestina e dessa fundação podem ser qualificados como mais "assistencialistas" que os do "CEAS", embora incluam oferta de educação e atenção à saúde, entre outros importantes serviços prestados à comunidade.

${ }^{23}$ Os nomes de logradouros no bairro trazem impressa a sua própria história, além do esforço pelo controle dos valores que lhe são atribuídos. Esse é o caso da rua principal que leva o nome de "Resistência", e cuja praça principal se chama "Praça das Decisões". Muitos desses nomes se multiplicam nas diversas travessas, que carregam o mesmo nome da rua que as origina, como: $1^{\mathrm{a}}, 2^{\mathrm{a}}$ $3^{\mathrm{a}}, 4^{\mathrm{a}}, 5^{\mathrm{a}}$ e até $6^{\mathrm{a}}$ travessas da Rua da Felicidade, ou $d a$ Paz, ou da Nossa Senhora da Paz, ou do Sossego etc. 
preocupação em assumir o controle das negociações que eram encaminhadas, além de definir uma imagem dos moradores como "pessoas lutadoras", o que também estava associado à idéia de guerra das "Malvinas".

O apoio de organizações diversas, como a organização-não-governamental CEAS, o MDF, políticos de partidos de esquerda e a própria Arquidiocese de Salvador teve especial importância para a resistência gestada no bairro. As informações que circulavam entre os ocupantes, advindas dessas organizações, ${ }^{24}$ são recorrentes nos relatos e parecem ter tido um papel relevante na concepção das ações e estratégias. Essas ações eram fortalecidas pela circulação de informações sobre a questão do terreno e uma possível posse pela Prefeitura. De acordo com os relatos do CEAS, sabiase que dívidas de impostos da família Visco com a prefeitura teriam acarretado uma expropriação na época, ainda não confirmada. Só em 13 de agosto de 1983, o jornal A Tarde publicou notícia sobre a desapropriação do terreno e o destino de inúmeras famílias que, mesmo assim, haviam sido deslocadas para a Fazenda Coutos. Desse modo, podemos ver como o movimento de organização dos moradores alimentava-se de uma rede não só de apoio logístico e material, mas também de informações que ajudavam a direcionar sua ação.

Apesar das transferências de moradores para Fazenda Coutos e de as notícias relatarem uma série de novas invasões no local, no período entre 1986 e 1987, a Malvinas nunca foi totalmente desarticulada. Uma das famílias que estudamos em profundidade é composta por membros que chegaram ao local no princípio da década de oitenta, e outros, do mesmo grupo familiar, no final da década, quando a violência cresceu e os mais velhos não podiam ficar sozinhos nos barracos. Essa casa é uma das que nunca foram derrubadas. As "derrubas" se concentraram nas faixas mais próximas da Avenida Paralela. Isso pode indicar que as investidas

${ }^{24}$ É preciso lembrar também a articulação de diversas pessoas envolvidas com a permanência da ocupação no local e que se denominavam "os amigos" das Malvinas, como alguns integrantes do Partido dos Trabalhadores (PT) e do Partido Verde (PV). da prefeitura eram mais tentativas de intimidar um maior alastramento, e menos de por fim a algo que já era demasiado grande e impossível de reverter. Várias matérias, conforme se relata a seguir, anunciam números alarmantes de moradores e apontam a possibilidade de esses números serem bem maiores que os oficiais.

Segundo dados de um relatório do CEAS, escrito em 1997, num primeiro levantamento, em 1988, o Bairro da Paz tinha 2.929 unidades de residência, então cabanas; em 1993, já eram 5.440; em abril de 1996, 5.800. E, em 1997, o bairro contaria com mais de 6 mil famílias, aproximadamente 35mil habitantes. Dados publicados em A Tarde de 09 de fevereiro de 1997 parecem desmentir essa informação, ao afirmar haver, no local, mais de 60 mil habitantes, segundo informações de autoridades da $12^{a}$ Delegacia. Essa última cifra é também bastante próxima à que nossa pesquisa obteve junto a informações diretas do Centro de Saúde da comunidade. Essa discrepância de dados entre diferentes fontes possivelmente revela dois tipos de contagem diferentes: a de membros do CEAS, preocupados em honrar os acordos realizados com prefeitura, devia estar contabilizando apenas as unidades familiares dentro da área poligonal legalmente negociada; e as outras fontes devem ter cadastrado também aquelas casas que estão fora da poligonal e que não têm, em princípio, direito ao título da terra ocupada, como as que estão dentro da poligonal.

A notícia, com chamada de capa, "Invasão das Malvinas está crescendo", intitulada "Favelados ressuscitam as Malvinas", aparece na Tribuna da Bahia de 05 de fevereiro de 1987. A matéria começa em tom de alarme: "Desde a semana passada que uma conhecida favela de Salvador está renascendo: as Malvinas". Após anunciar o renascimento da favela depois das ações da prefeitura anterior, a matéria expõe os motivos de um dos moradores, Renato Nunes Ramos, 27 anos, como razão típica para o retorno às Malvinas: "Só quero ter um lugarzinho para plantar e construir o meu coió". O texto traz, ao mesmo tempo, informações sobre a dimensão da ocupação e sobre as 
preocupações usuais daqueles que buscam um local para habitar, com a demarcação dos espaços para os barracos, a construção de fossa e área para uma pequena horta. ${ }^{25}$

Dois trechos dessa matéria chamam a atenção: em um, aparece a diversidade da fauna da região, que tantas vezes é relatada no Bairro da Paz: "Grande parte deles [dos habitantes] porta armas de fogo, mas apenas como meio de conseguir o que comer. 'Nós matamos preás, cotias e teiús que tem aqui', diz Renato". No segundo, há o temor em larga escala que provocava a invasão das Malvinas, atualmente sentido pelo Bairro da Paz: "Se para os novos invasores o local significa a possibilidade de ter onde morar e trabalhar, para os moradores das áreas vizinhas, a invasão, certamente, dá inicio a um pesadelo já bastante conhecido em Salvador: a ameaça dos marginais." A matéria é encerrada com uma denúncia de que as casas estavam começando a ser arrombadas e a haver tiroteios, mas que a polícia já havia sido informada e estava preparando a expulsão. Observa-se, aqui, uma ambigüidade no tratamento dos moradores da invasão, que são apresentados, num momento, como "pacíficos" e, no seguinte, como "perigosos". Essa indeterminação ecoa também nas práticas governamentais, com pequenas concessões simultâneas à repressão, além da percepção dos vizinhos mais ricos de que os ocupantes seriam todos "bandidos e marginais", ressaltando como a disputa, para além do pedaço de terra, envolvia também a identidade dos moradores.

No dia 07 de fevereiro de 1987, a Tribuna da Bahia publica uma nova destruição dos barracos. Um caminhão com funcionários da prefeitura e da Limpurb, escoltados por Policiais Militares armados de metralhadoras, segundo o relato, foram os responsáveis pela derruba através do uso

${ }^{25}$ Matérias dessa época relatam situações extremament difíceis de vida, de crescimento geográfico da ocupação e destruição da mata, com "desmatamentos à foice e facão”. Descreve-se a precariedade das moradias, em geral feitas de latas, papelão e palha de coqueiro. O lugar para plantar aparece como uma demanda além da moradia, que indica uma correlação direta com as dificuldades de obtenção de emprego e renda na grande metrópole, e com o acentuado contingente de imigrantes vindos do interior do estado. de muita violência. Após essa ação da PM, há vários relatos de uma grande manifestação organizada pelos moradores (das Malvinas e de várias outras localidades), que culminou com uma passeata até o Centro Administrativo, para cobrar ações do então governador, Waldir Pires. Nesse período, aparece a participação do MDF - Movimento em Defesa dos Favelados - como um agente de apoio à organização de movimentos pela habitação, entre eles o das Malvinas. Em 9 de março de 1987, ocorreu a desejada reunião do governador com vários representantes desse movimento, depois que mais de quatrocentas pessoas ocuparam duas das três pistas da Avenida Paralela. Na governadoria, estavam presentes representantes do Estado, da Assembléia Legislativa, da Prefeitura Municipal, da Câmara Municipal e do MDF. Após essa reunião, as matérias publicadas nos jornais mudaram o tom das notícias veiculadas. Passaram a se referir à invasão como um bairro e a noticiar algumas melhorias que foram gradativamente sendo implantadas, com a permanência no local.

No mesmo mês, aparece a primeira referência à mudança do nome, de Malvinas para Bairro da Paz, numa publicação da Tribuna da Bahia sob o título "Malvinas quer ser da Paz". Pela dimensão desse movimento geral de ocupação em diversas áreas da cidade, Fábio Santana, representante do governo do Estado, colocava como proposta principal da reunião uma "trégua no avanço das invasões", preocupado com a força da mobilização e até onde poderia chegar o crescimento das Malvinas, com novos "invasores". Decidiu-se, após esse encontro, que marcou a permanência das Malvinas na Avenida Paralela, pela criação de postos avançados de levantamento e cadastramento de seus ocupantes, nos quais moradores trabalharam em conjunto com o Estado e entidades sociais, de modo a legitimar a ocupação, mas, ao mesmo tempo, limitar a chegada de novos ocupantes, controlando aproveitadores e especuladores e envolvendo a própria comunidade na retenção do seu crescimento. Seguiram-se muitas desavenças internas, com boatos de que pessoas importantes do movimento estariam vendendo barracos e especulando sobre 
os terrenos invadidos, alguns desses aparentemente comprovados. Com isso, os moradores acabaram por solicitar policiamento à Casa Civil e, por intermédio do Pe. Confa (pároco local e membro do CEAS), conseguiram que fosse impedida a entrada de carros luxuosos, com material de construção, e que a comissão fosse, de alguma forma, protegida. Parte do material para construir os barracos foi retirada da floresta relativamente abundante do outro lado da pista da Avenida Paralela, o que preocupou a Comissão organizadora dos moradores, que tinha se comprometido a conter novas ocupações e construções, no acordo com a prefeitura. A preocupação do movimento de moradores do Bairro da Paz em honrar o compromisso com a Prefeitura, apesar de revelar a sua aceitação das novas regras do jogo com respeito à ocupação do espaço urbano, ditadas pelo Estado, denota, também, certo grau de protagonismo, pois procurava assumir por si mesmo o controle da ocupação. Ao mesmo tempo, esse início de negociações entre o Estado e a comunidade aponta o mútuo reconhecimento que surge entre eles, já que a comunidade não assumia um papel simplesmente reativo, mas procurava afirmar sua existência e seus direitos frente ao governo do estado, participando, inclusive junto a ele, do controle do crescimento da área.

"Malvinas foi sitiada" foi a manchete do dia 08 de abril de 1987. Aparece, nos jornais, a ação da polícia no bairro, após o acordo com o governo. Através dos relatórios do CEAS, entendemos que essa ação estava ligada ao atendimento de uma solicitação dos moradores, que queriam controlar a ocupação da área, evitando especuladores. Essa mudança de postura da polícia, indicada nos relatórios do CEAS, mostra a nova fase de legalização e reconhecimento do bairro. Isso parece ter sido também uma tentativa de acionar a polícia contra o aumento da violência e a ação do tráfico de drogas no bairro. ${ }^{26}$

Após as matérias de 1987, das quais

${ }^{26}$ É importante notar que, até hoje, a reivindicação por um posto policial não foi adequadamente atendida. $\mathrm{O}$ único posto existente foi construído pelos próprios moradores, que são muito mais reprimidos do que protegidos pelas ações policiais, segundo queixas recentes. trouxemos alguns exemplos, boa parte delas, em 1988, se dedica a denunciar as péssimas condições do novo bairro e a anunciar as melhorias que timidamente começaram a aparecer no local. Uma delas, e a mais relevante, em vigor até hoje, referese à implantação da rede elétrica pela Companhia Elétrica da Bahia (COELBA), que começava a levar iluminação pública para aquele local, embora com apenas alguns postes na área central. A partir desses postes, os moradores começaram a fazer "gatos", ${ }^{27}$ o que hoje é o motivo de inúmeros projetos assistencialistas da empresa para se fazer presente no bairro, em paralelo a um programa de combate ao furto de eletricidade, que está em vigor em todo o estado. Nas nossas visitas de campo, é freqüente observarmos o trânsito de automóveis da empresa, agentes circulando pelo bairro e vários projetos que anunciam o financiamento da Companhia em suas placas.

Em 14 de outubro do mesmo ano (1987), a Tribuna da Bahia publica a matéria "Governo começa a construção do Bairro da Paz”. Essa é a primeira matéria onde foi introduzida a mudança do nome. Essa mudança não foi por acaso. É fruto de outra ação organizada dos moradores, apoiados por amplos setores da sociedade, no sentido de começar a mudar a imagem do local, na cidade. Essa ação é uma preocupação dos moradores até hoje.

É preciso atentar que há duas conotações distintas para a "violência" sofrida no bairro. Uma é a repressão pelo poder público, da qual os moradores foram vítimas no passado, expressa na inversão semântica de "Malvinas" para "Bairro da Paz", e responsável, em grande medida, pela formação de uma auto-imagem "guerreira" em muitos segmentos de moradores, sobretudo muito visível entre jovens ativistas. Outra é a violência decorrente da presença de traficantes no local, que ainda ocorre, embora em menor grau que em períodos anteriores, como comentam seus moradores, muitas vezes em conivência com a presença da ${ }^{27}$ Fazer "gato" é uma expressão que significa fazer cone-
xões ilegais de energia entre os postes de iluminação pública e as casas. 
polícia militar, que é acusada de oprimir moradores muito mais do que reprimir o crime.

Os anos de 1987 e 1988 foram ricos em notícias das Malvinas e, em seguida, do Bairro da Paz, nos jornais. 1987 parece ter sido o ano de uma grande mudança, fruto da ação organizada dos moradores em conjunto com organizações civis. Em 14 de outubro de 1987, a Tribuna da Bahia informa que “... hoje, o Bairro da Paz já respira dias melhores com luz elétrica, água encanada que chega a algumas casas construídas de bloco, escolas de primeiro grau do Estado e do município, linhas de ônibus." Há uma lacuna de notícias entre os anos de 1989 e $1997 .{ }^{28} \mathrm{Em} 09$ de fevereiro de 1997, é publicado em A Tarde: "Malvinas vira Bairro da Paz, mas criminalidade permanece”. Essa matéria faz uma análise da violência e das mortes que tornaram o Bairro da Paz famoso e temido na cidade. Essa imagem de violência é ponto recorrente nos relatórios do CEAS, quando se referem à criação do Conselho de Moradores, que formou uma central de distribuição de notícias e informações para tentar mudar essa imagem.

Essas dimensões associadas da luta na formação do Bairro da Paz (especialmente da perspectiva do atual Conselho de Moradores) permite entendê-lo no contexto dos "novos movimentos sociais", na medida em que o movimento não objetiva uma ação política stricto sensu, mas um controle ativo sobre a identidade do lugar e seus habitantes. O atual Conselho de Moradores foi criado em novembro de 1992, em concorrência com a primeira Associação de Moradores, dado o descrédito de muitos residentes, que acusavam essa última de manter ligações espúrias, em interesse próprio, inclusive com o governo carlista. Já o novo Conselho, assessorado pelo CEAS e por Ernestina, aproxima-se mais do PT.

A chegada de Ernestina, em 1991, leiga italiana representante da paróquia de Mantova, trouxe muitos recursos e atraiu uma impressionante

${ }^{28}$ Provavelmente, devido à interrupção da coleta de informações para o banco de dados consultado. Mas é possível também que isso represente um desinteresse da mídia pelo bairro, uma vez que ele deixou de ser tão combatido. infra-estrutura para o local. ${ }^{29}$ Essa personagem é muito mencionada pelos moradores e mantém fortes relações com membros das pastorais, da Fundação Dom Avelar e do atual Conselho de Moradores, que ela ajudou a fundar e do qual participou ativamente. Os relatórios do CEAS dizem, também, que os agentes da pastoral, além das atividades relacionadas às escolas comunitárias e à área de saúde, atuavam para formar uma associação comunitária que contasse com membros ligados à Igreja e a outras áreas, para gerar novas lideranças mais comprometidas com a comunidade.

Ernestina foi e ainda é importante representante da Fundação Dom Avelar, e comprou terrenos no Bairro da Paz com capital de doações de sua paróquia na Itália. Segundo relato, envolto por uma atmosfera mítica, quando Ernestina chegou ao Bairro da Paz e construiu uma das primeiras casas de tijolo do bairro, os moradores foram encorajados a construir também as suas com material permanente. Até então, não se erguia nenhuma casa de alvenaria, pois havia o risco de intervenção policial para derrubar as moradias.

Isso coincide com uma redefinição de políticas públicas de habitação. Após quase dez anos de extinção do Banco Nacional da Habitação (BNH), em 1995-96, o Estado iniciou um programa de melhorias em áreas degradadas, em Salvador e em outros municípios da RMS - O Programa Viver Melhor. Esse programa foi financiado pelo programa Habitar Brasil e Pró-Moradia (intermediado pela Caixa Econômica Federal) e alcançou mais de quarenta áreas em toda a cidade. A partir do Programa Viver Melhor, se passa a atuar mais intensivamente em melhorias habitacionais de áreas degradadas já ocupadas, visando manter as populações nos assentamentos de origem e não removê-los, como se intentou em outros momentos (Gordilho, 2000, p. 161). Ou seja, mesmo quando os moradores percebem essas mudanças como

\footnotetext{
${ }^{29}$ As instalações da Fundação Dom Avelar, com seus projetos de assistência social e da Cidade Mãe, com atividades culturais para crianças e jovens, o centro comunitário - depois transformado em sede do Conselho. de Moradores -, cinco paróquias, cinco equipadas creches da Santa Casa de Misericórdia, a residência das freiras e padre, entre outras.
} 
frutos de suas ações e vontades - que também existiram e imprimiram marcas nesse processo - suas demandas tiveram maior efetividade porque coincidiram com novas diretrizes de políticas públicas.

O período de resistência contra as intervenções do governo do estado se encerra em meados da década de oitenta, quando o processo de distensão militar culmina com as eleições presidenciais e estaduais, que levam Sarney à Presidência da República e Waldir Pires ao governo do estado da Bahia. A partir daí, o movimento de moradores se fortalece cada vez mais. Em meados da década de noventa, aparecem os relatos de movimentos e passeatas de moradores, que começam a exigir, e a conseguir, equipamentos públicos e melhorias para o bairro. $\mathrm{O}$ fortalecimento do terceiro setor, nessa década, tem seu referente no bairro e, até hoje, ONGs, como Onda Azul e AVSI, e associações, como o Conselho de Moradores e as cooperativas, ocupam lugar importante na captação de recursos para a comunidade. Desde o início dos anos dois mil, é possível observar um fortalecimento de outros movimentos de ação política lato sensu, como os movimentos de jovens negros, do Hip Hop e as diversas instituições ligadas às religiões. ${ }^{30} \mathrm{Mesmo} \mathrm{o} \mathrm{candomblé,} \mathrm{mar-}$ ginalizado por décadas, apresenta indicativos de empoderamento no bairro e em toda a cidade, operando como marcador identitário e racial de grupos negros. É comum encontrar terreiros constituindo Associações Civis - ou já constituídas - para solicitar verbas públicas, para desenvolver projetos sociais no bairro (bem como por todas as áreas pobres da cidade). Por outro lado, projetos internacionais também chegam ao local, como o "Gente que Faz a Paz”, desenvolvido em parceria pela Universidade Internacional da Paz e Fundação Dom Avelar (com diversos patrocínios nacionais e estrangeiros).

Com altos e baixos, a história do Bairro da Paz permite situar a ação de seus moradores nos

\footnotetext{
${ }^{30}$ Este fortalecimento pode ser compreendido no quadro do surgimento dos "novos movimentos sociais", com suas reivindicações calcadas em questões identitárias e suas formas de participação disseminadas entre a população, bem como sua articulação em rede com outras instituições e organização, construindo um canal de diálogo entre o imediatamente local (a vida cotidiana no bairro) e as tendências e recursos globais.
}

termos do que Teixeira denominou "participação cidadâ". Sem ter um projeto político explícito relacionado diretamente a algum partido, os residentes se engajam em formas variadas de ação e participação que, a partir de sua experiência histórica de mobilização pela moradia, trazem à baila questões relativas a suas identidades e lugar ocupado no mundo contemporâneo. Assim, jovens são capacitados em informática, comunicam-se através da Internet no Telecentro do bairro, aprendem capoeira, música, teatro, dança fabricam instrumentos musicais e fazem reciclagem. Jovens e adultos participam de cursos e cooperativas, melhorando suas possibilidades de obtenção de renda. Mas, sobretudo, o bairro prossegue discutindo os problemas de inserção e cidadania, mesmo que seu cotidiano ainda seja cravado de dificuldades e violência.

Ao longo da história do bairro, visualizamos uma luta pelo seu estabelecimento, acompanhada pela disputa, no campo simbólico, em torno do valor atribuído ao local. ${ }^{31}$ Essa arena de contestação é formada por instituições públicas e privadas, bem como por "novos atores sociais" que ganharam espaço, sobretudo, a partir da década de oitenta (Teixeira, 2001; Touraine, 2005). Na análise da consolidação do bairro, podemos acompanhar as relações, muitas vezes conflituosas, entre essas instituições e esses atores, bem como a emergência daquele local em si mesmo como a de um ator social que se organiza a partir da própria vivência de seus habitantes, colocando suas reivindicações no que poderíamos chamar de um plano político "mais amplo". Além disso, podemos perceber a importância dos vínculos criados com associações diversas (ONG’s, Igreja Católica e facções da esquerda partidária) e como essa rede de relações foi fundamental para a consolidação do bairro e a conquista de melhorias. ${ }^{32}$

${ }^{31}$ Como bem nos lembra Bourdieu (2001), o espaço nas
cidades não é um mero “dado” objetivo, mas eivado de
valorações que posicionam seus ocupantes nas hierar-
quias sociais vigentes.
${ }^{32}$ No artigo “Exclusão social, desafiliação e inclusão social
no estudo de redes sociais de famílias pobres
soteropolitanas”, analisamos, em detalhes, como a con-
figuração de redes familiares e religiosas podem operar
na atenuação da vulnerabilidade social de grupos do
Bairro da Paz (Hita; Duccini, 2006). 


\section{NOTAS FINAIS}

No presente artigo, procuramos mostrar como as transformações ocorridas nos contextos urbanos de pobreza, correlatas a processos estruturais mundiais, foram acompanhadas pela emergência de novos atores sociais. A partir de um caso empírico, ressaltamos as formas de ação de algumas das associações que têm tido mais relevância e êxito nas mobilizações desse bairro pobre de Salvador, na sua luta por direitos sociais e melhoria das condições de vida. Analisando recortes de jornais locais, relatórios de uma ONG que sempre apoiou o movimento de moradores e suas narrativas, entre outras bases de dados, distinguimos alguns momentos que marcam essas relações entre pobreza, emergência de um novo ator e suas diferentes relações com o poder público e com organismos de caráter diverso. Um dos principais pontos a destacar é a multiplicidade dessas conexões e a impossibilidade de se distinguir uma relação causal unívoca entre uma situação de pobreza e um modo de mobilização popular.

É preciso levar em conta que foram necessários mais de quinze anos (dezoito ou quase vinte e três, se pensarmos na primeira invasão, no início da década de oitenta) de trabalho de base desta comunidade, que enfrentou diversas crises e desafios pela sua consolidação e direito à permanência em terras de interesse imobiliário, de conflitos ambientais e políticos, e que contou com o apoio de entidades como o CEAS e MDF, políticos de esquerda, além de recursos de grupos internacionais (especialmente italianos e ligados à rede católica) no seu processo de consolidação. Esse trabalho de base permitiu a formação de um tecido associativo e fez desse bairro um importante protagonista nas lutas pelo direito à moradia em Salvador, nos anos de 1987, 1993 e 1996. Também propiciou importantes conjunturas de discussão de políticas habitacionais para populações de baixa renda em todo o Brasil.

Hoje, a vida participativa do bairro alcança moradores que poderiam ser considerados "excluídos”, numa visão apressada. Pessoas e famílias que apresentam características que as tornariam socialmente vulneráveis - como cor da pele, baixo nível de educação formal, idade avançada, histórico de migração, presença de grande número de crianças na unidade doméstica, família monoparental e com chefia feminina - encontram várias formas de inserção em redes locais de sociabilidade. Os grupos religiosos, sem dúvida, ocupam lugar importante entre essas formas de inserção, não apenas por seu apelo afetivo, mas também por constituírem bases para ações mais amplas, principalmente de cunho cultural, como cursos de capacitação em informática e artesanato, por exemplo. Apesar das persistentes carências materiais do bairro - o colégio de nível médio encontra-se numa sede improvisada, pequena e precária, há apenas um posto de saúde, permanecem casas que sequer têm banheiro etc. podemos perceber um constante movimento de atração de recursos culturais e simbólicos para o bairro, a partir do engajamento ativo de alguns moradores em várias formas de associação e parcerias com o poder público e privado. Essa participação tem possibilitado a inserção dos residentes, principalmente os jovens, num mundo cultural globalizado e informatizado, no qual informações circulam sem fronteiras. Com isso, podemos observar, hoje em dia, um esforço de atores locais por construir sua própria identidade e imagem e não apenas receber passivamente as "etiquetas" que lhes são atribuídas na cidade, mesmo sem negar os problemas que ainda enfrentam, como a violência, a precariedade de serviços e uma imagem deteriorada.

Dessa forma, é possível interpretar a ação dos moradores e grupos constituídos do Bairro da Paz no contexto de surgimento de "novos movimentos sociais" que operam através de uma participação cidadã. Sua luta alcança o âmbito do reconhecimento através do esforço pelo autocontrole da imagem do bairro e de seus moradores na cidade, ao passo que as identidades forjadas ultrapassam as fronteiras do puramente local, inserindose numa dinâmica global em seus efeitos.

(Recebido para publicação em fevereiro de 2007) (Aceito em agosto de 2007) 


\section{REFERÊNCIAS}

BOURDIEU, Pierre. O conhecimento pelo corpo. In Meditações Pascalianas. Rio de Janeiro: Bertrand Brasil, 2001

BOURDIEU, Pierre; WACQUANT, LoÏc. As artimanhas da razão imperialista. Estudos Afro-Asiáticos, Rio de Janeiro, v. 24 , n. 1 , p. 15-33, 2002.

CARVALHO, Inaiá; PEREIRA, Gilberto. Como anda Salvador. Salvador: Edufba, 2006.

CASTEL, Robert. La metamorfosis de la cuestión social. Una crónica del salariado. Buenos Aires: Barcelo; México: Paidós, 1997.

CASTELLS, Manuel. O Poder da identidade. São Paulo: Editora Paz e Terra, 2002. (A era da informação: economia, sociedade e cultura; v.2).

DUHAU, Emílio. As novas formas da divisão social do espaço nas metrópoles latino-americanas: uma visão comparativa a partir da cidade do México. Caderno CRH: revista do Centro de Recursos Humanos da UFBA, Salvador, v. 18, n. 45, set./dez., 2005. (Dossiê: Urbanidade Contemporânea)

ELIAS, Norbert. O processo civilizador. Rio de Janeiro: Zahar, 1994

; SCOTSON, John L. Os estabelecidos e os outsiders. Rio de Janeiro: Zahar, 2000.

FERREIRA, João Sette W. Globalização e urbanização subdesenvolvida. São Paulo em Perspectiva. São Paulo, v. 14, n. 4, out./dez., 2000.

FORUM LARR/ LASA. From marginality of the 1960s to the "New Poverty" of Today". Latin American Research Review, [S.l.], v. 39, n. 1, 2004.

GIDDENS, Anthony. Sociologia. Porto Alegre: Artmed, 2005 .

GLEDHILL, John. Citizenshipand the social geography of deep neo-liberalization. Anthropologica, [S.l.], n. 47, 2005.

GOHN, Maria da Glória. A contribuição de Alain Touraine para a produção do conhecimento na sociologia urbana: sujeitos coletivos e multiculturalidade. In: ENCONTRO ANUAL DA ANPOCS, 30. 2006. Caxambu. CD-Rom.

GORDILHO, Ângela. Limites do habitar: segregação e exclusão na configuração urbana contemporânea de Salvador e perspectivas no final do século XX. Salvador: Edufba, 2000 .

HITA, Maria Gabriela; DUCCINI, Luciana. Exclusão social, desafiliação e inclusão social no estudo de redes sociais de famílias pobres soteropolitanas. In: SEMINARIO INTERNACIONAL: PROCESOS DE URBANIZACIÓN DE LA POBREZA Y NUEVAS FORMAS DE EXCLUSIÓN SOCIAL. Cidade do México: CLACSO-CROP-IIS/UNAM, 2006.
IVO, Anete B. Leal. The redefinition of the social issue and the rethoric on poverty during the "90s". In: CIMADAMORE; DEAN; SIQUEIRA (Eds.) The poverty of the state. Reconsidering the role of the State in the struggle against global poverty. Buenos Aires: CLACSO Books, Series CLACSO/CROP, 2005. p. 65-90,

; SCHERER-WARREN, Ilse. Pobreza, dádiva e cidadania. Cadernos CRH: revista do Centro de Recursos Humanos da UFBA, Salvador, v. 17, n. 40, p 11-16 jan./abr., 2004. (Dossiê: Pobreza, Justiça e Dádiva).

JELIN, Elizabeth. Ciudadania, derechos e identidad. Latin American Research Review, [S.l.], v. 39, n. 1, 2004. (FORUM LARR/ LASA. From Marginality of the 1960s to the "New Poverty" of Today).

KOWARICK. Lúcio. Viver em risco: sobre a vulnerabilidade no Brasil urbano. Revista Novos Estudos CEBRAP, São Paulo, n. 63, 2002.

LABBÉ, Juan Fernández. Pobreza urbana: políticas habitacionales e intentos para el fin de los asentamientos precarios en Chile. ¿De la exclusión social a la integración?". In: SEMINARIO INTERNACIONAL: PROCESOS DE URBANIZACIÓN DE LA POBREZA Y NUEVAS FORMAS DE EXCLUSIÓN SOCIAL. Cidade do México: CLACSO-CROP-IIS/UNAM, 2006.

LAVALLE, Arián Gurza; CASTELLO, Graziela. As benesses deste mundo: associativismo religioso e inclusão socioeconômica. Novos Estudos CEBRAP, São Paulo, n. 68, 2004.

LAVINAS, Lena. Transferências de renda: o 'quase tudo' do sistema de proteção social brasileiro. In: SEMINARIO INTERNACIONAL: PROCESOS DE URBANIZACIÓN DE LA POBREZA Y NUEVAS FORMAS DE EXCLUSIÓN SOCIAL. Cidade do México: CLACSO-CROP-IIS/UNAM, 2006.

MACAGNO, Lorenzo. Cidadania e cidades (aventuras e desventuras do multicultualismo). Espaço \& Debates, São Paulo, v. 23, n. 43/44, p.51-59, jan./dez., 2003.

PRYSTHON, Ângela. O cosmopolitismo e a cidade: transitando por velhos e novos conceitos. Espaço \& Debates, São Paulo, v. 23, n. 43/44, p.60-70, jan./dez., 2003.

ROBERTS, Bryan. From marginality to social exclusion: from laissez faire to pervasive Engagement. Latin American Research Review, v. 39, n. 1. 2004. (FORUM LARR/ LASA, From Marginality of the 1960s to the "New Poverty" of Today).

SCHWARTZMAN, Simon. As causas da pobreza. Rio de Janeiro: Ed. FGV, 2004.

TEIXEIRA, Elenaldo. O local e o global: limites e desafios da participação cidadã. São Paulo: Cortez, 2001.

TOURAINE, Alain. Um novo paradigma. Para compreender o mundo de hoje. Petrópolis: Vozes, 2005.

VALLADARES, Lícia. A gênese da favela carioca: a produção anterior às ciências sociais. Revista Brasileira de Ciências Sociais, São Paulo, v. 15, n. 4, p. 5-31, 2000. 
DA GUERRA À PAZ: o nascimento de um ator social no contexto da "nova pobreza" urbana em Salvador/Bahia

\section{Maria Gabriela Hita Luciana Duccini}

O artigo analisa a história da formação e consolidação do Bairro da Paz, um dos mais pobres da cidade de Salvador, através num arquivo de notícias de jornais locais e de um relatório de acompanhamento realizado pelo Centro de base neste material e de dados coletados diretamente em campo, propomos uma interpretação da luta dos moradores para permanecer no local, que destaca sua própria agência. Dessa forma, pode-se observar que a organização local, apoiada por movimentos sociais, políticos e de setores da Igreja Católica, não se limitou à obtenção do direito de moradia, num primeiro momento, nem apenas à obtenção de melhorias de urbanização, num segundo momento. $\mathrm{O}$ modo de atuação dos ocupantes da área também voltou-se para a construção de uma identidade, de "moradores locais", articulando-se com movimentos e entidades diversas, pressionando e buscando controlar a própria ocupação, bem como a própria imagem do local, o que os aproxima do modelo chamado de "novos movimentos sociais". O argumento central é que, diante de um fenômeno como a "nova pobreza" urbana (se é que pode ser assim definido), os atores sociais também encontram novas formas de articular sua ação, mesmo sem terem necessariamente um projeto político explícito, nos moldes tradicionais.

PALAVRAS-CHAVE: favelas, nova pobreza, atores sociais, representações sociais, KEYwORDs: slums, new poverty, social Salvador.

FROM WAR TO PEACE: the of a birth social actor in the

"new poverty" in Salvador/Bahia

\section{Maria Gabriela Hita \\ Luciana Duccini}

This paper analyzes the history of the formation and consolidation of Paz's Neighborhood (Paz in portuguese means Peace), one of the poorest of the city of Salvador, through a series of local newspapers articles and a report of attendance of CEAS (in english, Center d'accompaux locaux et d'un rapport of Studies and Social Action). Based in d'Etudes et d'Action Sociale - CEAS. Ce his material and in data collected directly matériel ainsi que les données recueillies in the field, we propose an interpretation directement sur le terrain, nous of the residents' fight to stay at their permettent de proposer une interprétation lace that points out their own agency. de la lutte des habitants pour rester dans In this way, it can be observed that the cet endroit et de mettre en évidence leur ocal organization, supported by social mode de vie. C'est ainsi que l'on peut and political movements, and by sectors observer que l'organisation locale of the Catholic Church, was not limited soutenue par des mouvements sociaux, o obtaining the right of occupancy, in politiques mais aussi par des secteurs de its beginning, nor, later, to obtaining of l'Eglise catholique ne s'est pas limité, dans urbanization improvements. The un premier temps, à l'obtention du droit performance of the area occupants also d'habitation ni simplement, dans un urned to the construction of an deuxième temps, à l'obtention d'une dentity of "local resident", articulated amélioration del'urbanisation. La manière with several entities and movements, d'agir des occupants de l'endroit a pressing and striving for to control their également mené à la construction d'une own occupation, as well as their own identité des "habitants locaux" qui se sont mage, in a way that approximates them rattachés à des mouvements et des entités of the model called "new social diverses, ont essayé de faire pression et movements". The central argument is ont cherché à contrôler l'occupation en that, before a phenomenon as the urban soi ainsi que l'image du lieu, ce qui les "new poverty"(if that can be defined rapprochent du modèle appelé "nouveaux like this), the social actors also find new mouvements sociaux". Largument cenforms of articulating their action, even tral est que, face à un phénomène tel que without an explicit political project. "la nouvelle pauvreté" urbaine (si on peut la définir ainsi), les acteurs sociaux ont aussi trouvé de nouvelles formes d'organisation de leur action, même sans avoir obligatoirement un projet politique explicite selon des modèles traditionnels. acteurs sociaux, représentations sociales, Salvador.

Maria Gabriela Hita - Doutora em Ciências Sociais pela UNICAMP. Professora Adjunta do Departamento de Sociologia da Universidade Federal da Bahia. Autora de "A família em Parsons: pontos, contrapontos e modelos alternativos". Anthropológicas. v. 16, p. 109-148, 2005 e "Igualdade, identidade e diferença(s): feminismo na re-invenção de sujeitos. In: Gênero em Matizes. Bragança Paulista: EDUSF- Ed. da Universidade de São Francisco, 2002, p. 319-351.

Luciana Duccini - Antropóloga, Bacharel em Comunicação Social pela UMESP e doutora em Ciências Sociais pela UFBA com a tese "Diplomas e Decás: Re-interpretações e identificação religiosa de membros da classe média no Candomblé". Trabalha em antropologia urbana na área de estudos sobre identidades pessoais e coletivas, classes sociais, religião e pobreza. É consultora do CEBRAP e bolsista FAPESB no projeto coordenado pela Profa. Dra. Maria Gabriela Hita. 